\title{
Eqstudios EGerenciales
}

Journal of Management and Economics for Iberoamerica

Artigo de pesquisa

\section{Modelo de negócio e estratégia de inovação de uma empresa brasileira de alimentos}

Frederico Andreis Beneli Donadon *

Professor, Eixo Tecnológico de Gestão e Negócios, Centro Estadual de Educação Tecnológica Paula Souza - CEETPS, Taquaritinga, Brasil. fredadministracao@bol.com.br

David Ferreira Lopes Santos

Professor Associado, Faculdade de Ciências Agrárias e Veterinárias, Universidade Estadual Paulista - UNESP, Jaboticabal, Brasil. david.lopes@unesp.br

\section{Resumo}

Este estudo tem como objetivo analisar o modelo de negócios, a estratégia e a capacidade de inovação de uma empresa alimentícia brasileira. Para tanto, metodologicamente, conduziu-se um estudo de caso sustentado em dados coletados através de entrevistas balizadas pela ferramenta de gerenciamento estratégico Business Model Canvas e pelo Octógono da Inovação, que foram validados com o Software IRAMUTEQ. Os resultados configuram um modelo de negócio amparado por uma estrutura interna de pesquisa e desenvolvimento (P\&D), voltado para o lançamento de novos produtos de maior valor agregado, direcionados a demandas de consumo e de regulação. Este cenário competitivo, diverge dos resultados de outras pesquisas, principalmente no tocante ao baixo nível de investimento em 'P\&D, ao caráter incremental das inovações, à dependência de commodities e à falta de efetividade nas atividades inovativas.

Palavras-chave: empresa de alimentos; Brasil; estratégias de inovação; capacidade inovativa.

\section{Modelo de negocio y estrategia de innovación de una empresa brasileña de alimentos}

\section{Resumen}

Este estudio tuvo como objetivo analizar el modelo de negocio, la estrategia y la capacidad de innovación de una industria alimentaria brasileña. Para tal fin, metodológicamente, se realizó un estudio de caso basado en datos recopilados en entrevistas marcadas por el Business Model Canvas y el Octágono de Innovación, los cuales fueron validados con el software IRAMUTEQ. Los resultados constituyen un modelo de negocio respaldado por una estructura interna de investigación y desarrollo, orientada al lanzamiento de nuevos productos con mayor valor agregado, dirigidos a las demandas de consumo y regulación. Este escenario competitivo difiere de los resultados de otras investigaciones, principalmente con respecto al bajo nivel de inversión en investigación y desarrollo, la naturaleza incremental de las innovaciones, la dependencia de los productos básicos y la falta de eficacia en las actividades innovadoras.

Palabras clave: empresa de alimentos; Brasil; estrategias de innovación; capacidad innovadora.

\section{Business model and innovation strategy of a Brazilian food company}

\section{Abstract}

This study aimed to analyze the business model, the strategy, and the innovation capacity of a Brazilian food industry. To this end, methodologically, a case study was conducted based on data collected by interviews marked by the Business Model Canvas and Innovation Octagon, which were validated with the software IRAMUTEQ. The results constitute a business model supported by an internal structure of research and development, aimed at the launch of new products with greater added value, directed towards the demands of consumption, and regulation. This competitive scenario differs from the results of other research, mainly with regard to the low level of investment in research and development, the incremental nature of innovations, the dependence on basic commodities, and the lack of effectiveness in innovative activities.

Keywords: food company; Brazil; innovation strategies; innovative capacity.

* Autor para dirigir correspondência.

Classificações JEL: 032; M21.

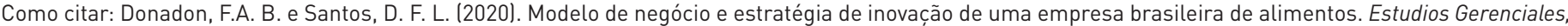
36(156), 337-350. https://doi.org/10.18046/j.estger.2020.156.3634

DOI: https://doi.org/10.18046/j.estger.2020.156.3634

Recebido: 15-jul-2019

Aceito: 2 -jul-2020

Publicado: 28 -set-2020 


\section{Introdução}

É crescente o interesse de acadêmicos, gestores e outros profissionais de mercado por modelos de negócios diferenciados, que suportem atividades inovativas bemsucedidas, especialmente quanto à aplicação eficaz da estratégia e da capacidade de inovação, tidas como relevantes na criação de valor e da captação de vantagens competitivas, e como forma de diferenciar-se da concorrência.

Embasados nessa concepção, estudos contemporâneos têm exaltado a relevância de um contexto organizacional favorável à criação, uso e compartilhamento de informações, ideias e conhecimentos, mais condizentes com a exigência das novas demandas e que possam levar a empresa a alcançar uma maior competitividade (Wu, 2011; Cheng, Chang e Li, 2013; Ramos e Zilber, 2015; Bencke, Gilioli e Royer, 2018).

Denota-se, assim, que uma empresa se revela inovadora não somente por seus produtos e processos tecnologicamente inovadores, mas também por suas aspirações de inovar, altamente articuladas à estratégia de inovação, à capacidade de inovação e a um modelo de negócio focado na contínua dinâmica do mercado (Ginting, 2015; Ceretta, Reis e Rocha, 2016).

Diante desse contexto, notadamente neste século, o setor global de alimentos tem passado por um processo de valorização e diversificação, associado a inúmeros fenômenos socioeconômicos que têm fomentado a necessidade diversificada de produtos com novas características e apelosmais adequados à mudança de perfil e aos hábitos dos consumidores; principalmente face ao aumento de renda de diversos estratos sociais (Arcese, Flammini, Lucchett e Martucci, 2015; Bresciani, 2017; Franceschelli, Santoro e Candelo, 2018).

Os números da indústria de alimentos mostram que - Brasil faturou $\mathrm{R} \$ 642$ bilhões em 2017, correspondente a $9,8 \%$ do produto interno bruto (PIB) do país. Já em 2018, segundo a Associação Brasileira da Indústria de Alimentos (Abia, 2019), a receita nominal foi de $R \$ 656$ bilhões, um aumento de 2,08\% em relação ao ano anterior,

Dados mais recentes da Pesquisa Industrial Anual (PIA) mostram que a agroindústria alimentícia representa $11,9 \%$ do total das indústrias de transformação do Brasil (39.795 empresas), com empregabilidade de 20,9\% dos trabalhadores inseridos neste setor (1,623 milhões, segundo o Instituto Brasileiro de Geografia e Estatística - IBGE, 2017): uma configuração que destaca o setor industrial alimentício como o maior setor gerador de empregos do país, e o segundo maior setor em número de empresas.

Em que pese a importância econômica e social do setor de alimentos no Brasil, uma vez que o crescimento do agronegócio brasileiro baseado na produtividade das atividades agropecuárias in farm nos últimos 40 anos (1980/2020), concedeu ao país o posto de principal exportador de alimentos do mundo, denota-se que a preponderância dessa evolução está nos produtos in natura.

Além disso, resultados da Pesquisa de Inovação Tecnológica do Brasil (PINTEC) apontam para uma taxa de investimento média de 1,28\% da receita, entre 1998 e 2014 , em pesquisa e desenvolvimento (P\&D); sendo que, no último triênio avaliado, o investimento foi de 1,13\%. Em adição, menos de 0,03\% dos trabalhadores do setor alimentar estão envolvidos em atividades de $P \& D$, resultados esses, inferiores à média nacional de $2,98 \%$ de gastos com P\&D e dos $0,16 \%$ dos trabalhadores ocupados com atividades de P\&D, conforme dados do IBGE (2017).

A literatura especializada registra que a interação entre os investimentos em $P \& D$ e o crescimento competitivo é uma questão primordial para qualquer país que busca caminhos para alcançar um nível de produção, de renda e de distribuição, compatíveis com suas necessidades econômicas e sociais (Quandt, 2012; Raimundo, Batalha e Torkomian, 2017; Santos e Magrini, 2018).

Dados relacionados ao nível de investimentos e de recursos humanos dedicados à inovação, indicam que a geração de tecnologia e de inovação na indústria de alimentos brasileira, ainda é pouco expressiva. Resultados apurados pela PINTEC (IBGE, 2017) assinalam um maior foco de inovação no setor voltado para melhoria da qualidade de produtos: $50,2 \%$ frente a $31 \%$ para a ampliação da gama de novos produtos, e $21 \%$ para abertura de novos mercados; uma situação que sugere que poucos esforços de inovação se incorporam de maneira explícita e sistemática à formulação estratégica das empresas agroindustriais de alimentos no Brasil.

O escopo dessas discussões denota, ainda, que há poucos estudos da literatura recente, sobre a indústria alimentícia brasileira, que evidenciam a interação entre inovação, estratégia e capacidade para inovar, e o modelo de negócio desenvolvido na organização (Gianezini, Alves, Techemayer e Révillion, 2012; Stefanovitz e Nagano, 2014).

Nagano, Stefanovitz e Vick (2014, p. 163) corroboram esta conclusão quando destacam "a carência de trabalhos empíricos que analisem a realidade das práticas propostas no mundo organizacional, em especial no Brasil" e propõem "abordagens mais sistêmicas para o entendimento e gerenciamento do processo inovador".

Nesse contexto, a questão que motivou este trabalho centra-se na seguinte reflexão: há, efetivamente, articulação e alinhamento entre a gestão do modelo de negócios e estratégia e a capacidade/estrutura para inovar no ambiente organizacional de uma empresa brasileira de alimentos de grande porte?

À vista do exposto, configura-se como objetivo deste estudo analisar o modelo de negócios, a estratégia, e a capacidade de inovação de uma empresa de alimentos brasileira, para um melhor entendimento de como as referidas ferramentas estão estruturadas, e como são geridas e aplicadas de maneira formal e/ou informal na organização, visando atender a novas demandas de consumo e regulação, e a manter a competitividade em um mercado cada vez mais dinâmico e exigente.

Para alcançar o objetivo proposto, este estudo está organizado em mais 4 seções, a partir da introdução: a segunda delas expõe o referencial teórico, a terceira configura a metodologia e a quarta seção trata dos resultados. Ao final, se encontram as conclusões. 


\section{Referencial teórico}

\subsection{Modelos de negócio, estratégias de inovação e capacidade} de inovação

De acordo com a pesquisa realizada para esse estudo, a expressão "modelo de negócios" adquiriu proeminência com o desenvolvimento das Tecnologias da Informação e Comunicação (TICs) e dos negócios e-business no início da década de 1990. Segundo Osterwalder (2004), o conceito surge na literatura em 1960, ou seja, não é recente na realidade prática das organizações (Ceretta et al., 2016; Scaciotta, Guerrazzi e Fernandes, 2019).

0 design do modelo de negócio de uma organização, surge a partir da análise da interação entre a estrutura de funcionamento em relação a componentes e ligações, cuja interação é fundamental para gerar um sistema capaz de suportar a decisão de mudança, e a elaboração de uma estratégia específica, ancorada no próprio ambiente competitivo (Bonazzi e Zilber, 2014; Amit e Zott, 2015; Lopes, Kissimoto, Salerno, Carvalho e Laurindo, 2016; Zhao, Pan e Chen, 2018).

Como a estratégia inovativa de uma organização pode ser viabilizada com sucesso a partir da observação cuidadosa de seu modelo de negócio, é possível conceituar "estratégias de inovação" como a forma pela qual um modelo de negócio é explorado, no intuito de se obter vantagens (CasadesusMasanell e Ricart, 2010; Baden-Fuller e Morgan, 2010; DaSilva e Trkman, 2014, Brem e Viardot, 2017).

Autores como Osterwalder e Pigneur (2010) destacam que o entendimento da configuração de um modelo de negócios, possibilita explorar as conexões do mesmo com a estratégia de negócios, a gestão da inovação e a teoria econômica envolvidas, de forma a definir a maneira pela qual a organização fornece valor ao cliente; leva-o a pagar por ele e o converte em lucro (Teece, 2010).

Infere-se, pelo contexto, que a "estratégia de inovação" e a "capacidade de inovação" são tidos como importantes recursos organizacionais para o modelo de negócio praticado, pois, além de definirem a condução do processo de geração de vantagens competitivas, permitem a criação de novos produtos e/ou processos produtivos, aperfeiçoamento das organizações e utilização de processos inovativos de marketing (Ramos e Zilber, 2015; Frank, Cortimiglia, Ribeiro e Oliveira, 2016; Del Carpio Gallegos e Miralles, 2018).

Denota-se, portanto, na atualidade, a relevante necessidade da interação entre o modelo de negócio, a estratégia e a capacidade de inovação, principalmente em ambientes que demandam mudancas constantes em decorrência das inovações tecnológicas, das recentes necessidades dos clientes e dos novos formatos de negócios IChristensen, 1997; Lopes et al., 2016; Tarapuez, Guzmán e Parra-Hernández, 2016).

\subsection{Estudos Empíricos no Brasil sobre a indústria de alimentos}

A construção do presente trabalho está embasada não só na observação da empresa pesquisada, mas também em estudos empíricos que possam proporcionar um melhor entendimento, diálogo e comparação com os resultados obtidos na literatura sobre a indústria alimentícia do Brasil, notadamente nas duas últimas décadas. Justifica-se a delimitação do período anteriormente proposto, a partir da concepção de Conceição e Almeida (2005), que assim especificam o avanço no setor de alimentos, no país:

[...]. No caso específico do Brasil, a condição de estabilização econômica do país a partir de 1995 permitiu ao consumidor acesso a novos produtos e condições de compra. [...]. Assim, o comportamento do consumidor, influenciado pela nova condição econômica, pelo acesso à informação e pelo contato com novos produtos provenientes do mercado externo, estabeleceu uma intensificação da competição, exigindo novas estratégias do setor no que se refere à inovação (Conceição e Almeida, 2005, p.602).

Dentre os aspectos críticos apontados por autores de pesquisas empíricas de destaque sobre a indústria de alimentos no Brasil, no período anteriormente especificado, destacam-se:

i. Baixo nível de investimento e pouca intensidade em P\&D - decorrente do fato de que grande parte do desenvolvimento de novas tecnologias de processo e produto é realizada por agentes externos como fornecedores de equipamentos e insumos, instituições públicas de P\&D ou outros setores.

Gouveia (2006, p.32), ao discorrer sobre diversificação e apostas em novas tecnologias da indústria de alimentos, conclui que "[...] a indústria de alimentos brasileira [...] precisa de Investimentos em pesquisa e desenvolvimento (P\&D) com o objetivo de criar novos produtos de maior valor adicionado". [...]. Segundo a autora, "algumas empresas sequer possuem ainda um departamento de P\&D".

Cabral (2007, p.104) corrobora o anteriormente exposto quando, em estudo para identificar as variáveis organizacionais que determinam a probabilidade e a intensidade de inovações na indústria de alimentos do Brasil, registra que "as empresas alimentícias serão mais efetivas na atividade inovativa, se adotarem como estratégias a alavancagem de seus esforços em P\&D".

César, Mori e Batalha (2010, p.361), em artigo sobre inovações tecnológicas em embalagens destinadas à indústria de alimentos, enfatizam que “[...] observa-se (na indústria de alimentos) um paradoxo dado pela baixa intensidade de investimento em P\&D e alta intensidade inovativa (produto e processo)".

Révillion (2011, p.10) ratifica a concepção dos inúmeros pesquisadores em relação ao baixo investimento em $P \& D$ ao registrarem que "[...] No Brasil, esse baixo nível de investimento em P\&D ainda é uma realidade no setor processador de alimentos". 
Raimundo et al. (2017) ao abordarem a dinâmica tecnológica da Indústria Brasileira de Alimentos e Bebidas (IAB), no período de 2000 a 2011, com base nos indicadores fornecidos pela Pesquisa Industrial de Inovação Tecnológica (PINTEC), observam que: "[...] 0 investimento em P\&D das firmas ainda é relativamente baixo, sendo a estratégia tecnológica majoritária do setor a imitativa" (p.423). “[...]A proporção do investimento em P\&D sobre vendas na indústria de alimentos é relativamente baixa quando comparada a de outras indústrias" (p.426).

ii. Caráter incremental das inovações na indústria alimentícia brasileira - com prevalência no setor do caráter incorporador, em detrimento do gerador de novas tecnologias.

César et al. (2010), no tocante ao caráter incorporador de novas tecnologias, concluem que “[...]. Há uma constante demanda por novos produtos no setor de alimentos. No entanto, devido aos padrões conservadores dos consumidores em relação às questões alimentares, tem-se um padrão de consumo estático, uma vez que as características do novo produto devem ser similares às daqueles existentes. Com isso, poucas rupturas tecnológicas são verificadas. Acrescenta-se o fato de que grande parte do conhecimento científico-tecnológico usado se origina em indústrias correlacionadas" (p.361).

Révillion (2011, p.10) argumenta que "seria de se esperar que o grau de inovatividade fosse limitado em sua intensidade (número restrito de novos lançamentos por unidade de tempo) e diversidade (pequeno número de variações dos atributos dos novos produtos lançados)". Segundo o autor "[...] A análise do perfil das inovações associadas à introdução de novos produtos alimentícios permite ilustrar o papel preponderante de inovações de caráter incremental, fruto de novas tecnologias de processo e/ou de novos ingredientes desenvolvidos por fornecedores".

iii. Regime de apropriabilidade frágil - dada a facilidade de replicação das tecnologias desenvolvidas.

Sidonio, Capanema, Guimarães e Carneiro (2013, p.351), em pesquisa sobre a importância e dinâmica da inovação da indústria de alimentos no contexto do complexo agroindustrial brasileiro, desenvolvido a pedido do BNDES - Banco Nacional do Desenvolvimento Econômico e Social, registram que "[...] o regime de apropriabilidade na indústria alimentícia pode ser considerado relativamente fraco, pois, em geral, as tecnologias desenvolvidas não são difíceis de serem replicadas e o sistema de propriedade intelectual é pouco eficaz". Segundo os autores, “[...] 0 regime de apropriabilidade relativamente fraco é um importante elemento para se compreender o baixo grau de ineditismo nessa indústria".

iv. Dependência excessiva de commodities - a preponderância da evolução do setor de alimentos no Brasil está nos produtos "in natura", que absorvem menos conteúdo tecnológico; em relação às commodities, a produção moderna é mais valorizada no mercado global.

Sidonio et al. (2013, p.334) observam que “[...] 0 Brasil vem se mostrando competitivo internacionalmente na produção de várias matérias-primas agropecuárias, não alcançando, entretanto, o mesmo desempenho nos manufaturados derivados delas, como no caso dos alimentos processados. [...]". Na concepção dos autores, entretanto, [...] “0 país não garantirá a supremacia alimentar se não processar seus produtos, se produzir apenas commodities".

v. Efetividade restrita em inovação organizacional e mercadológica e em relação à competência técnica e operacional, envolvendo produto e processo.

O Centro de Gestão e Estudos Estratégicos (CGEE) e a Empresa Brasileira de Pesquisa Agropecuária (Embrapa) desenvolveram o Projeto Alimentos 2014 - uma análise conjunta abrangente da importância do Brasil na sustentabilidade e sustentação da produção de alimentos - e destacam iniciativas orientadas para o futuro de médio e longo prazos, que buscam fortalecer o papel do país na oferta global de produtos e serviços ligados ao consumo de alimentos. Os pesquisadores envolvidos no referido projeto registram as seguintes sugestões:

“[...] 0 estudo identifica um grande potencial para a criação de novas empresas de base tecnológica capazes de explorar nichos de mercado de maior valor agregado. Para a exploração de todo esse potencial será necessário enfrentar desafios para ampliar e tornar a atividade inovativa mais eficiente, visando à geração e à transferência de tecnologia, em estreita colaboração com grupos de pesquisa de institutos e universidades, de modo a incentivar a criação de novos negócios e produtos alimentícios de base tecnológica, portanto de maior valor agregado" (Embrapa e CGEE, 2014, p. 45).

vi. Sistema de propriedade intelectual pouco eficaz (reduzida produção de patentes, por exemplo).

Raimundo et al. (2017, p.434) discorrem sobre o fato de que grande parte das inovações são novidades no âmbito interno da empresa, o que denota, na concepção dos autores, a baixa capacidade tecnológica da Indústria Brasileira de Alimentos e Bebidas (IAB). Segundo os autores, “[...] é crescente o número de empresas que realiza inovações, mas decrescente a quantidade de empresas que inovam simultaneamente em produto e processo", em situação que "[...] mostra contenção na ampliação da linha de produtos e na agregação de valor, uma vez que novos produtos exigem modificações mais importantes nos seus processos de produção e intensificam a dinâmica tecnológica da indústria alimentícia".

Os excertos anteriormente expostos serão utilizados à frente, na sequência deste estudo, quando da comparação com os resultados obtidos empiricamente no estudo de caso, visando verificar se as referidas conclusões se confirmam ou não no cenário pesquisado. 


\subsection{Ferramentas e software utilizados na validação dos dados compilados}

As bases conceituais e o software utilizados, estão especificados na Tabela 1.

As ferramentas e software anteriormente expostos foram selecionados por melhor se adequarem ao objetivo proposto no presente estudo.

\section{Procedimentos metodológicos}

A pesquisa tem abordagem metodológica pautada nos estudos qualitativos, de cunho bibliográfico e de natureza exploratória, aplicada em estudo de caso único, desenvolvido por meio das seguintes etapas: i) observação do cenário pesquisado, ii) acompanhamento e análise da rotina do processo produtivo, iii) análise de documentos internos, mediante permissão da empresa e iv) entrevistas pessoais (semiestruturadas e em profundidade), com gestores envolvidos no processo.

As informações foram coletadas em entrevistas, no período de julho de 2017 a maio de 2018, com interrupção nos meses finais do ano de 2017, à época da safra anual período de 04 meses, entre outubro e fevereiro de cada ano, coincidente com a safra das culturas processadas e/ ou industrializadas pela empresa envolvida - quando grande parte dos funcionários estão alocados em setores estratégicos da empresa e as tentativas de agendamento de entrevistas com os mesmos revelam-se, às vezes, infrutíferas; razão pelo qual a $2^{\mathrm{a}}$ etapa das entrevistas ocorreu entre março e maio de 2018.

\section{Análise dos resultados}

\subsection{Contextualização da empresa selecionada}

Entre as agroindústrias alimentares identificadas no universo de indústrias de alimentos localizadas no interior do estado de São Paulo (Polo Regional Centro Norte do estado), selecionou-se a empresa em questão, que demonstrou interesse pela pesquisa e disponibilidade para a sua realização. Por questões de sigilo, sua identificação foi preservada, sendo a mesma identificada apenas como Alfa, com perfil caracterizado na Tabela 2.

Tabela 1. Síntese das dimensões das bases conceituais e software utilizados

\begin{tabular}{|c|c|c|c|}
\hline Base & BMCCanvas & Octógono Inovação & IRAMUTEQ \\
\hline Referencial teórico & $\begin{array}{l}\text { Business Model Generation } \\
\text { (Osterwalder e Pigneur, 2010) }\end{array}$ & $\begin{array}{l}\text { Gestão da Inovação na prática/ } \\
\text { Innoscience (Scherer e Carlomagno, } \\
\text { 2009; Scherer, Bignetti e Carlomagno, } \\
\text { 2009) }\end{array}$ & $\begin{array}{l}\text { IRAMUTEQ (Interface de R pour } \\
\text { les Analyses Multidimensionnelles } \\
\text { de Textes et de Questionnaires) } \\
\text { (Ratinaud e Marchand, 2012) }\end{array}$ \\
\hline Objetivo & $\begin{array}{l}\text { Entendimento do modelo de negócio } \\
\text { empreendido }\end{array}$ & $\begin{array}{l}\text { Diagnóstico do potencial de inovação } \\
\text { da empresa }\end{array}$ & $\begin{array}{l}\text { Tratamento e validação dos dados } \\
\text { obtidos }\end{array}$ \\
\hline Dimensões analisadas & $\begin{array}{l}\text { - Parceiros } \\
\text { - Atividades } \\
\text { - Recursos } \\
\text { - Proposta de valor } \\
\text { - Relacionamento } \\
\text { - Canais } \\
\text { - Clientes } \\
\text { - Fontes de receita } \\
\text { - Estrutura de custo }\end{array}$ & $\begin{array}{l}\text { - Estratégia } \\
\text { - Cultura } \\
\text { - Estrutura } \\
\text { - Pessoas } \\
\text { - Processo } \\
\text { - Funding } \\
\text { - Liderança } \\
\text { - Relacionamentos }\end{array}$ & $\begin{array}{l}\text { - Análise de similitude } \\
\text { - Nuvem de palavras }\end{array}$ \\
\hline
\end{tabular}

-BMC: Business Model Canvas

Fonte: elaboração própria.

Tabela 2. Perfil da empresa Alfa

\begin{tabular}{ll}
\hline Porte & Grande \\
Fundação & $<1992$ \\
Produtos & A empresa produz mais de 700 itens, entre molhos, atomatados, vegetais em conserva, condimentos, doces, geleias, \\
& gelatinas, achocolatados em pó, sopas e macarrão instantâneo, além de linhas especiais, como a Premium, Light, Livre e \\
& Institucional (130 deles fabricados para comercialização da marca própria e os demais para 70 marcas de grandes redes de \\
& supermercados). Lidera o segmento de doces (goiabadas) e a segunda marca no segmento de atomatados em stand ups. \\
Gestão & Empresa familiar (Sociedade Ltda.) \\
Número de Funcionários & $>1.300$ empregos diretos e aproximadamente 5.000 empregos indiretos, em parques industriais no Brasil. \\
Mercado Consumidor & $\begin{array}{l}\text { Nacional (70\% da receita) e internacional (30\% da receita). A empresa atende cerca de } 60 \text { países, } 1 / 3 \text { deles conquistados nos } \\
\text { últimos dois anos. }\end{array}$ \\
\hline
\end{tabular}

Fonte: elaboração própria. 


\subsubsection{Entrevistas Aplicadas nos gestores da Empresa Alfa}

Após submissão à empresa de documento formalizado sobre o objetivo da pesquisa e das condições para a sua realização, concluiu-se que a principal fonte de informação para o estudo seriam as entrevistas. A atenção foi direcionada ao nível estratégico da organização e, a partir do organograma da empresa Alfa, definiu-se o direcionamento das entrevistas para 07 executivos, além do sócio fundador da organização, num total de 08 entrevistados. Na sequência, as entrevistas foram realizadas, conforme mostra a Tabela 3.

\subsection{Resultados da aplicação do BMC Canvas na empresa Alfa}

Evidencia-se, na sequência (Tabela 4), o entendimento, em detalhes, do modelo de negócio praticado, na perspectiva dos entrevistados, a partir das nove dimensões do BMC Canvas, concebidas por Osterwalder e Pigneur (2010).

Denota-se, pelo exposto, que o modelo de negócio da empresa está estruturado no amplo conhecimento das necessidades dos clientes, e no interesse em atender essas necessidades. Esse fato fica claro na proposta de valor e nos recursos-chaves que são amplamente direcionados ao consumidor. Não obstante, o desenvolvimento de dezenas de linhas de produtos e de um portfólio com centenas deles, corrobora-se o foco da empresa no atendimento às necessidades dos clientes e sua atenção para os diferentes perfis de consumidores de produtos alimentícios.

Depreende-se que, para viabilizar essa proposta de valor, as parcerias com outras instituições são fundamentais, bem como uma atenção com a qualidade de toda a cadeia de valor. Foi notória a importância entregue pelos diretores, ao gestor principal da empresa que, na condição de sócio fundador, é ainda o principal líder responsável pelo direcionamento das decisões de novos produtos, parceiroschaves, e o próprio controle financeiro da empresa.

\subsection{Resultados da aplicação do Octógono da Inovação na empresa Alfa}

\subsubsection{Resultados da estratégia de inovação da empresa}

O diagnóstico dos elementos para a estratégia de inovação na empresa é apresentado na Tabela 5.

Tabela 3. Detalhamento das entrevistas aplicadas

\begin{tabular}{|c|c|c|c|c|c|}
\hline Cargo & Formação & Atuação & Entrevistas & Datas & Ferramentas \\
\hline Sócio-Diretor & Química & 40 anos & $\begin{array}{l}02 \text { entrevistas de } 50 \\
\text { minutos cada }\end{array}$ & 07/08/2017 12/09/2017 & $\begin{array}{l}\text { BMC Canvas e } \\
\text { Octógono }\end{array}$ \\
\hline $\begin{array}{l}\text { Gestor da } \\
\text { Área comercial }\end{array}$ & Produção Financeiro & 10 anos & $\begin{array}{l}02 \text { entrevistas de } 50 \\
\text { minutos cada }\end{array}$ & 06/03/2018 11/03/2018 & $\begin{array}{l}\text { BMC Canvas e } \\
\text { Octógono }\end{array}$ \\
\hline Gerente marketing & Marketing & 25 anos & $\begin{array}{l}01 \text { entrevista com } \\
\text { duração de } 02 \text { horas }\end{array}$ & $16 / 05 / 2018$ & $\begin{array}{l}\text { BMC Canvas e } \\
\text { Octógono }\end{array}$ \\
\hline
\end{tabular}

Fonte: elaboração própria.

Tabela 4. Devolutiva do Canvas da empresa Alfa

\begin{tabular}{|c|c|}
\hline Dimensões & Diagnóstico \\
\hline Segmentos de clientes & $\begin{array}{l}\text { A empresa produz para consumidores próprios, além de para mais } 70 \text { marcas de grandes redes de supermercado do país e } \\
\text { para cerca de } 60 \text { países no exterior ( } 20 \text { deles conquistados nos últimos dois anos). É, portanto, um modelo de negócio focado em } \\
\text { mercado consumidor de grupos de clientes com perfis e demandas similares, alinhados com a proposta de valor da empresa } \\
\text { e com atratividade relevante para o negócio por serem segmentos robustos de clientes, com perspectivas de rentabilidade } \\
\text { promissoras. }\end{array}$ \\
\hline $\begin{array}{l}\text { Relacionamento com } \\
\text { clientes }\end{array}$ & $\begin{array}{l}\text { A empresa coloca as estratégias de relacionamento como fator dos mais relevantes para a fidelização dos clientes. } 0 \text { aprendizado } \\
\text { a partir da interação e envolvimento dos usuários no processo promove a agregação de valor aos produtos, o que torna } 0 \\
\text { marketing da cocriação uma fonte de vantagem competitiva e de rentabilidade para a empresa. }\end{array}$ \\
\hline Proposta de valor & $\begin{array}{l}\text { Previamente a empresa procura avaliar o comportamento do consumidor, analisando seus desejos em relação a determinado } \\
\text { produto. Assim, torna-se mais fácil definir quais são os valores e benefícios que o cliente espera de um produto. Preço, praticidade, } \\
\text { funcionalidade, novidade, design, status (no caso de grupos), conveniência, finalidade e usabilidade são valores atualmente muito } \\
\text { procurados, além principalmente da saudabilidade. }\end{array}$ \\
\hline Atividades- chave & $\begin{array}{l}\text { Entre as ações mais importantes que a empresa usa para fazer funcionar seu modelo de negócio está o empenho em relação ao } \\
\text { marketing, engajamento de stakeholders e uso da tecnologia de informação. O zelo em relação à produção, vendas e distribuição } \\
\text { dos produtos, bem como um processo eficiente de desenvolvimento na produção, contrato com fornecedores confiáveis e } \\
\text { parceiros, aquisição de matéria prima e embalagem de boa qualidade, bem como o envio do produto de forma adequada são } \\
\text { etapas que merecem atenção redobrada por parte do controle de qualidade da empresa. }\end{array}$ \\
\hline
\end{tabular}


Tabela 4. Devolutiva do Canvas da empresa Alfa. (Continuación)

$\begin{array}{ll}\text { Parcerias-chave } & \text { Em relação às parcerias-chave que auxiliam na boa condução do modelo de negócio proposto, a empresa valoriza sobremaneira } \\ \text { o conhecimento oriundo das universidades, centros de pesquisas, bem como de outros órgãos públicos, estratégia de } \\ \text { cooperação com as empresas concorrentes e as relaçães comprador-vendedor, que promovem o desenvolvimento econômico } \\ \text { e empresarial, inovação e transferência de tecnologia, além de possibilitarem a obtenção de custos mais favoráveis, redução de } \\ \text { riscos ou incertezas, aumento da facilidade de aquisição de recursos e atividades de cooperação, que podem garantir à empresa } \\ \text { o fornecimento de matéria-prima durante todo o ano. } \\ \text { É fator de relevância para a empresa a definição do modo como ela pode gerar receita satisfatória dentro do seu modelo de } \\ \text { Fontes de renda } \\ \text { negócio. Esta dimensão é centralizada pela empresa no gestor principal, pois envolve o capital gerado pela mesma a partir } \\ \text { propriamente ditas, mas também em relação a desenvolvimento de produtos inovadores, precificação e formas de pagamento. } \\ \text { Os envolvidos na organização como um todo são conscientes de que todas as etapas que contribuem para o funcionamento do } \\ \text { modelo de negócio da mesma têm um custo. Minimizar custos em todas as áreas do modelo de negócio a partir da definição } \\ \text { dos recursos-chave, atividades-chave e parcerias importantes faz parte da administração dos custos, de forma a alavancar um } \\ \text { melhor diferencial competitivo que permita oferecer produtos com qualidade e precificação atrativas para o cliente. A estrutura } \\ \text { de custo da empresa tem suas variantes em relação a custos fixos (pagamentos de funcionários, aluguel predial, e outros), } \\ \text { bem como custos variáveis que envolvem a variação cambial, custo de energia elétrica e outros insumos, ou ainda, na prática } \\ \text { da economia de escala la empresa vende quantidade a um preço mais baixo, consequentemente aumenta a saída de produtos } \\ \text { e a produção) e da economia de escopo (vantagem de custo que a empresa desfruta por usar a mesma estrutura de canais de } \\ \text { distribuição para viabilizar a colocação de uma ampla diversidade de produtos). }\end{array}$

Fonte: elaboração própria.

Tabela 5. Devolutiva do Octógono da Inovação da empresa Alfa

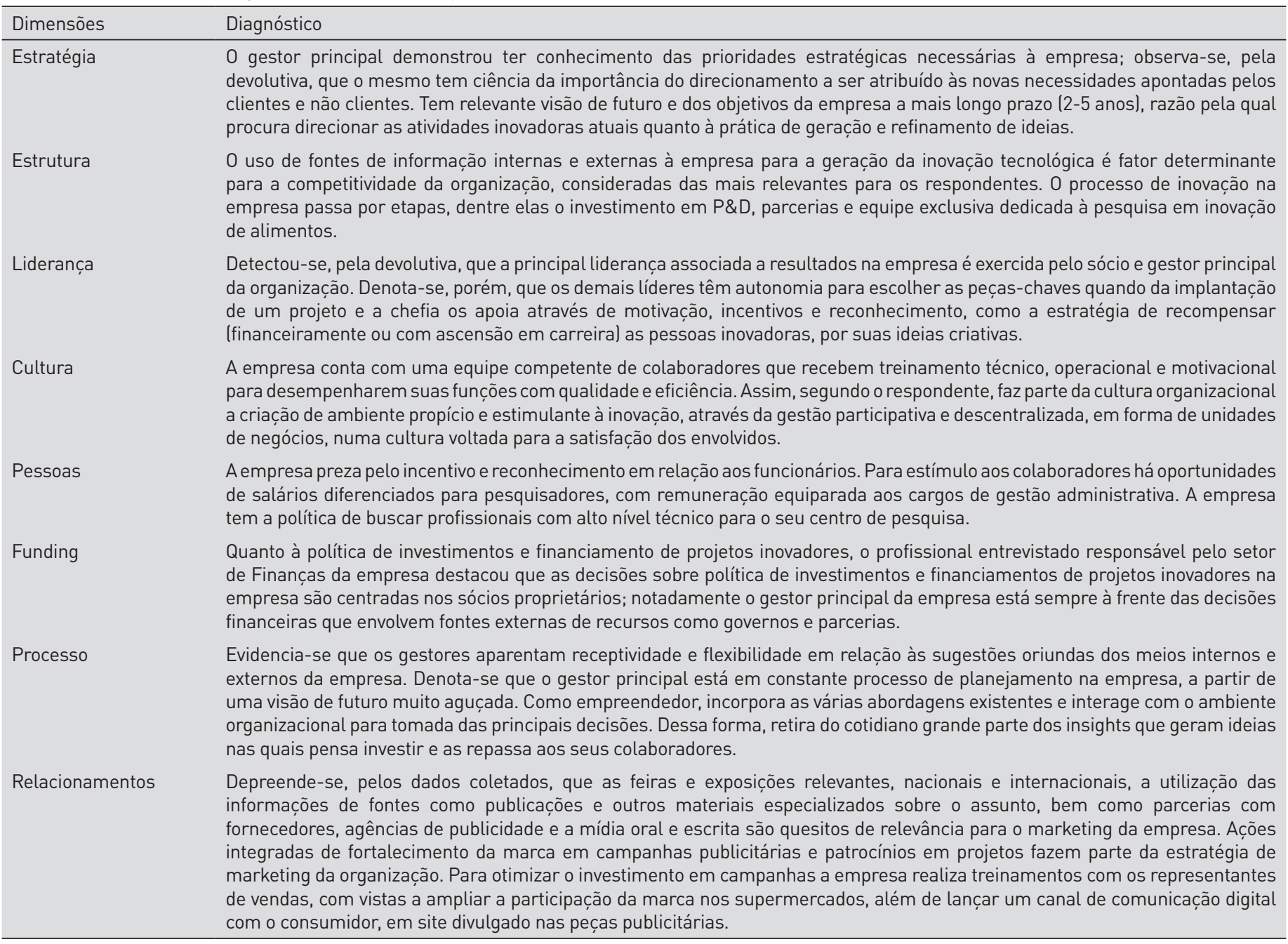

Fonte: elaboração própria. 
No cenário pesquisado, denota-se que "a inovação está essencialmente relacionada à descoberta, experimentação, desenvolvimento, imitação e adoção de novos produtos, novos processos de produção e novos arranjos organizacionais" (Dosi, 1988, p.222). Para Freeman (1975, p.256) “(...) embora a teoria econômica tradicional ignore em grande medida a complicação da ciência e da tecnologia mundiais e considera o mercado como o meio ambiente, a mudança tecnológica é um aspecto de importância decisiva do ambiente das firmas na maioria das indústrias e países".

Configura-se, pela devolutiva do Octógono da Inovação, que a competitividade inovativa da empresa Alfa chega ao mercado na forma de novos produtos e que a organização tem na estratégia de diversificação deles, o seu eixo principal; haja vista a gama de mais de 700 itens (130 deles fabricados para comercialização da própria marca e os demais para 70 marcas de grandes redes de supermercados).

0 desafio de estudar oportunidades de fornecimento para clientes que apresentam alto volume de consumo em um curto espaço de tempo, destaca o perfil empreendedor e dinâmico do gestor-líder, quando do uso de sua capacidade para identificar oportunidades e, através delas, ampliar a competitividade da empresa (Demil, Lecocq, Ricart e Zott, 2015).

\subsubsection{Resultados da capacidade e estrutura de inovação na empresa Alfa}

Evidencia-se, quanto à capacidade/estrutura de inovação da empresa Alfa, que a mesma não apresenta aspectos complicadores em relação aos recursos financeiros, já que a organização procura disponibilizar o montante necessário para a remuneração dos profissionais ligados à inovação, e para aquisição de tecnologia.

Quanto aos recursos de infraestrutura, observa-se na empresa uma evolução para as atividades de P\&D, como a existência de um centro de pesquisa em alimentos e softwares para projetos de reengenharia. Assim, a alocação de recursos financeiros que refletem o compromisso da empresa com a inovação, ao longo do tempo, é um processo contínuo.
Pelos relatos e observação in loco, a empresa destina recursos intangíveis às competências incorporadas em seus colaboradores e no grupo. Recursos esses, responsáveis pela capacidade inovativa, que engloba todo o corpo de conhecimentos tácitos e explícitos acumulados na empresa, e reverte-se como ativos de conhecimentos codificados nos registros internos da organização - sejam estes apropriáveis ou não - sob a forma de propriedade intelectual (Stefanovitz e Nagano, 2014).

A capacidade de identificar e avaliar a vantagem competitiva das características transferíveis e inovadoras dos funcionários, é outra prática de relevante importância estratégica na empresa, pois a valorização do capital humano reverte-se em vantagem competitiva, em termos de habilidades, especialização, disposição para trabalhar e insights para ideias inovadoras (Mcguirk, Lenihan eHart, 2015), conforme estrutura da capacidade de inovação da empresa Alfa, exposta na Tabela 6.

Pelas evidências observadas, deduz-se que um dos fatores primordiais para o sucesso da empresa, é o alinhamento e articulação das iniciativas de inovação, alicerçado pela definição clara das estratégias ao modelo de negócio praticado e aliado a um esforço conjunto na organização como um todo, com medidas eficazes que minimizam falhas na gestão e execução da dinâmica tecnológica da organização.

Depreende-se do contexto investigado, que a influência da empresa junto ao mercado é um fator estratégico de relevância e que a organização tem sua estrutura/ capacidade de inovação voltadas para a diferenciação frente aos concorrentes, o que evidencia a inovação em modelo de negócio, desdobrado em estratégias voltadas para novos produtos (Vils, Mazzieri, Rodrigues, Da Silva e de Queiroz, 2017).

Para Chesbrough (2010), uma das formas no auxílio à identificação de características inovativas é através da análise da dinâmica tecnológica da empresa. Face à concepção exposta, os principais processos inovativos tecnológicos, destacados dentre os muitos desenvolvidos pela empresa pesquisada, encontram-se expostos na Tabela 7.

Tabela 6. Estrutura da capacidade de inovação da empresa Alfa

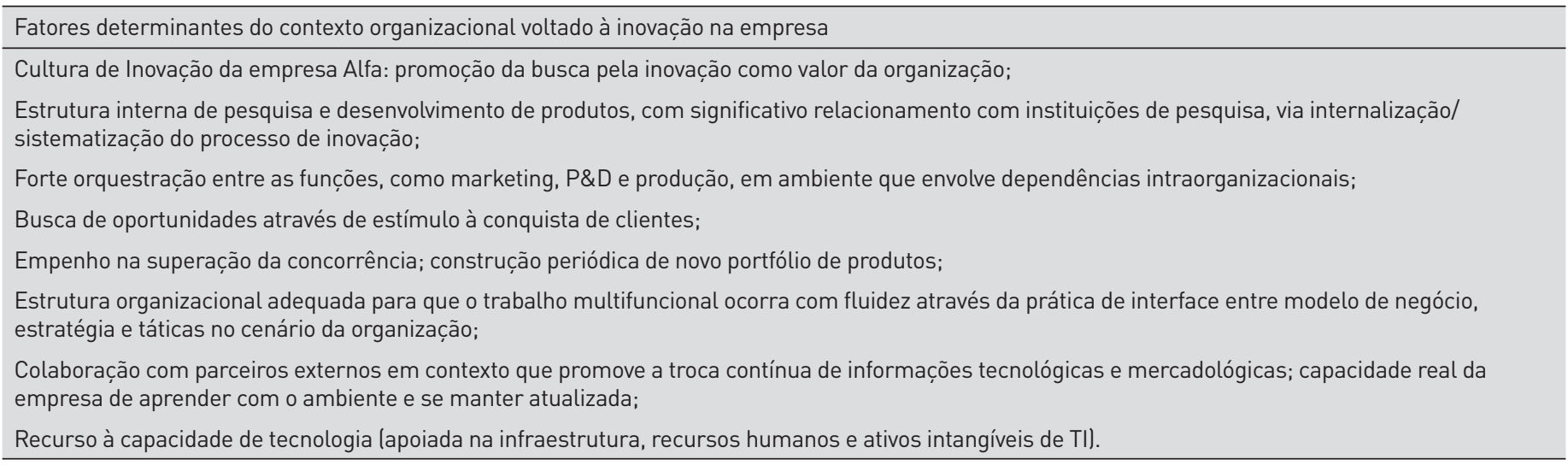

Fonte: elaboração própria a partir de Stefanovitz e Nagano (2014). 
Tabela 7. Dinâmica Tecnológica da empresa Alfa

\begin{tabular}{|c|}
\hline \\
\hline 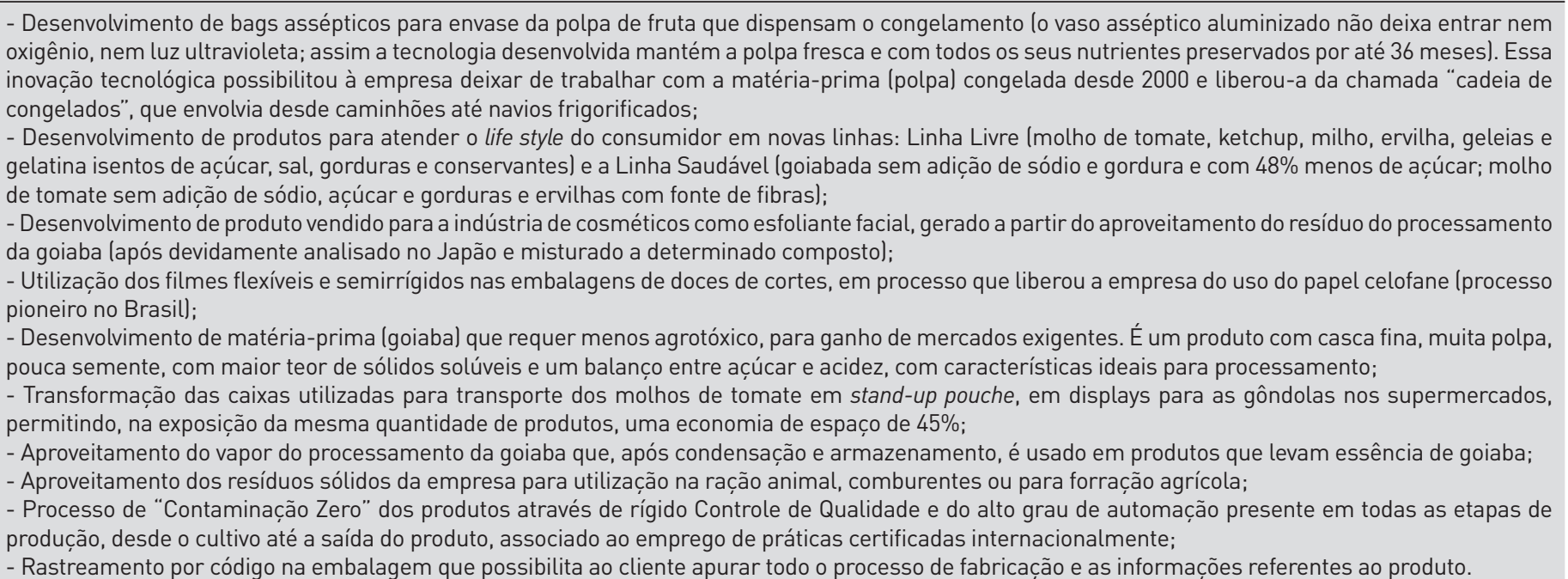 \\
\hline
\end{tabular}

Fonte: elaboração própria.

Infere-se pela análise dos fatores determinantes da inovação no contexto investigado (Tabela 7) que a estrutura da capacidade de inovação da empresa Alfa é amplamente influenciada ou definida pela estratégia de inovação e pelo modelo de negócio praticado.

\subsection{Resultados da validação dos dados compilados através do software IRAMUTEQ}

Para validação dos resultados expostos na pesquisa em relação ao modelo de negócio da empresa Alfa, sua estratégia de inovação e sua capacidade/estrutura de inovação, utilizou-se o IRAMUTEQ, com resultados obtidos a partir da análise de similitudes ou semelhanças, e por nuvem de palavras. Referidas análises são geradas a partir do Corpus Textual Temático (formado pelos vocábulos compilados nas entrevistas) e pelos respondentes (indivíduos identificados numericamente no software como Ind. 1, Ind.2, e assim sucessivamente, até Ind.8), conforme mostrado na Tabela 8.

Tabela 8. Identificação dos respondentes da empresa

\begin{tabular}{ll}
\hline Entrevistados [Ind.] & Cargo na empresa \\
\hline [Ind.1] & Sócio-diretor e gestor principal da empresa \\
[Ind.2] & Diretor Industrial \\
[Ind.3] & Gerente de Marketing e Institucional \\
[Ind.4] & Responsável pelo Centro de Pesquisa/Inovação \\
& em Alimentos \\
[Ind.5] & Responsável pela Área Agrícola \\
[Ind.6] & Diretor Comercial \\
[Ind.7] & Responsável pelo Setor de Finanças \\
[Ind.8] & Responsável pelo Recursos Humanos (RH) \\
\hline
\end{tabular}

Fonte: elaboração própria.

\subsubsection{Resultados da análise de similitude na empresa Alfa}

Nesta subseção do trabalho, inicialmente elaborou-se um mix do leque semântico das palavras mais frequentes dos entrevistados, com vistas a definir o Corpus Textual Temático (universo dos vocábulos selecionados). Recorreuse, neste procedimento, à compilação de dados nas devolutivas dos respondentes quanto a elementos voltados à compreensão do modelo de negócios atual da organização, estratégias de inovação, e capacidade/estrutura para inovação da mesma.

Para gerar a análise de similitude, o software IRAMUTEQ (Figura 1) selecionou do Corpus Textual Temático um universo de 181 palavras entre as mais citadas ao longo dos depoimentos e entrevistas, sendo a palavra "empresa" a que apresentou maior fator repetitivo (pronunciada 90 vezes ao longo dos discursos registrados) e "material" a de menor frequência (pronunciada apenas 03 vezes pelos respondentes).

Por questão de concisão, optou-se pelo registro das palavras com maior frequência repetitiva até a classificação 20, que foram intencionalmente expostas em ordem decrescente, com o intuito de relevar o aspecto classificatório em relação à força de expressão das mesmas nas coocorrências e correlações dos discursos dos entrevistados. Como os respondentes não apresentaram um discurso único, por se correlacionarem com diversas áreas, as palavras com maior fator repetitivo e a interpretação dos possíveis discursos estão expostas na Figura 1.

A partir da síntese classificatória dos vocábulos e discursos selecionados pelo IRAMUTEQ nas entrevistas aplicadas (Figura 1), o software IRAMUTEQ gerou a imagem em cores (Figura 2), projetada através de indicadores estatísticos, como resultado da análise de similitude. 


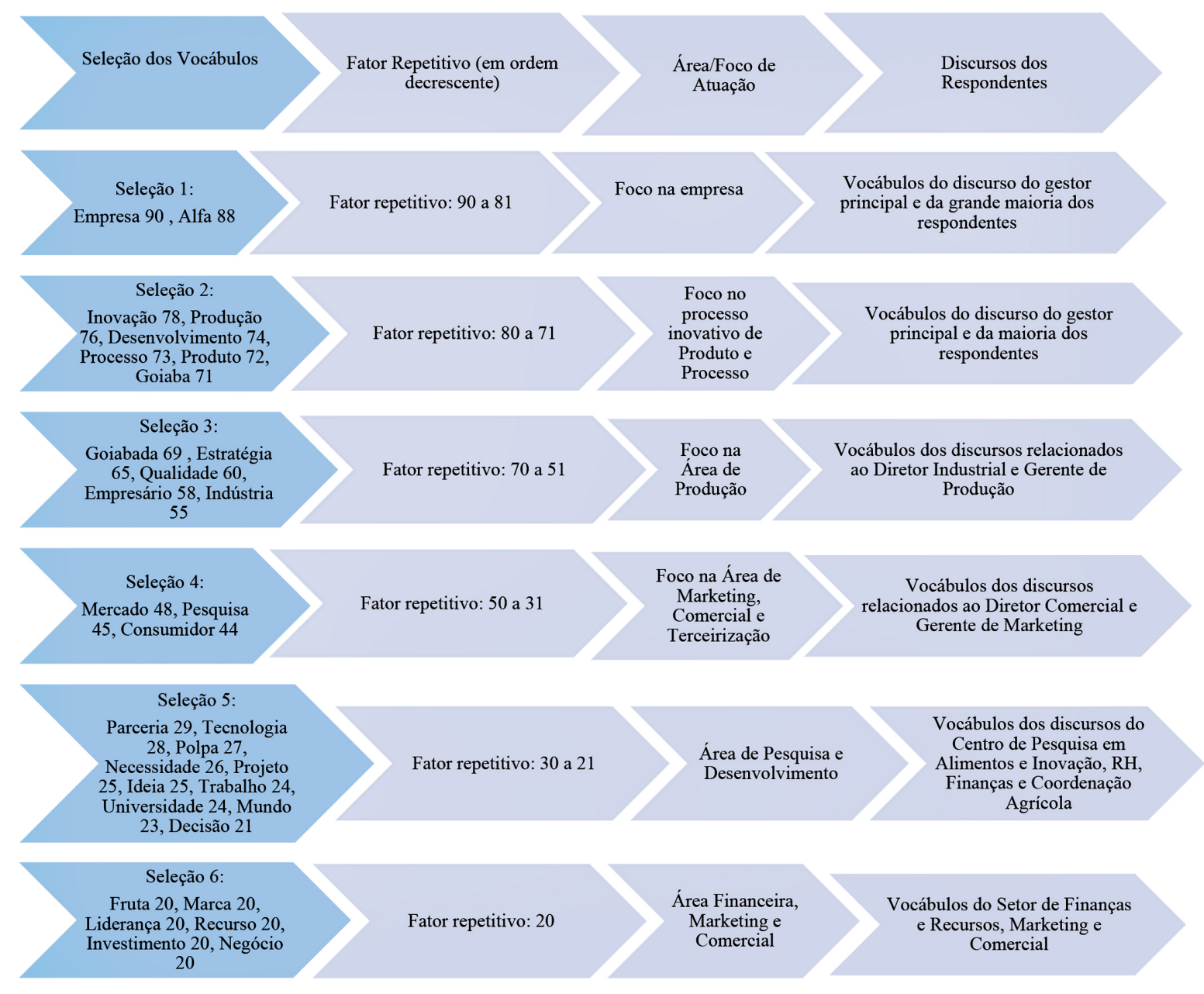

Figura 1. Síntese classificatória dos vocábulos e discursos selecionados pelo IRAMUTEQ nas entrevistas aplicadas Fonte: elaboração própria.

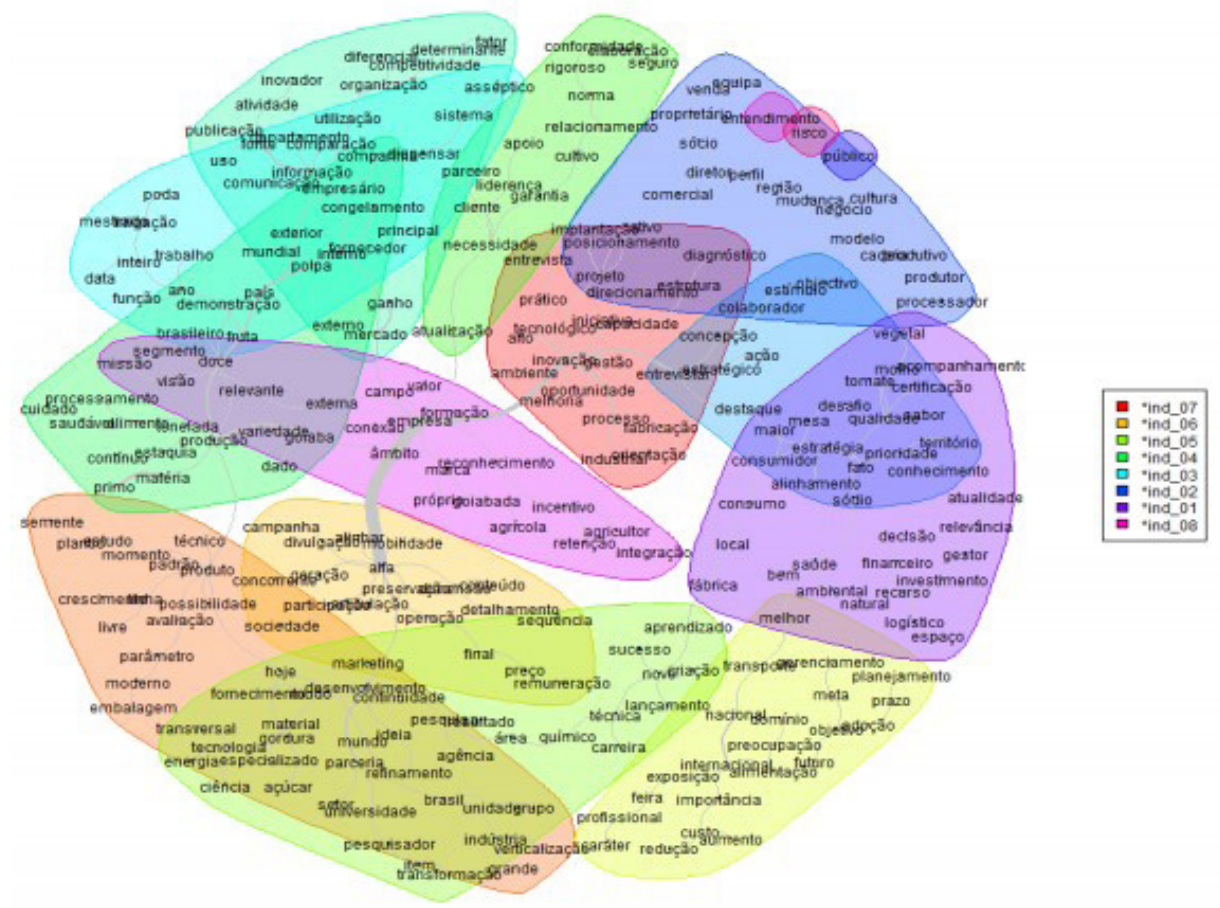

*Ind.: Entrevistados (Indivíduo 01 ao Indivíduo 08)

Figura 2. Resultado da análise de similitude da empresa Alfa

Fonte: elaboração própria. 
No resultado da análise de similitude, a cor Imais acentuada ou mais leve) e a espessura dos traços que unem as palavras, contêm discursos visuais com significados, cujas indicações de conexidade auxiliam na identificação da estrutura do campo representacional dos fatores envolvidos no Corpus Textual Temático (entrevistas) e aqueles associados às respostas dos entrevistados, identificados na legenda como indivíduos (Ind.1 a Ind.8). A identificação dos respondentes, através da concentração de cores, encontrase exposta na Tabela 9.

Evidencia-se, a partir do resultado da identificação dos respondentes por cor representativa (Tabela 9), que os vocábulos das devolutivas do gestor principal e do diretor industrial (há 22 anos na empresa Alfa e funcionário de alta confiança do gestor principal), transitam por praticamente todos os campos de cores.

0 exposto permite validar as características da atuação do líder da empresa (gestor principal), como elo na gestão estratégica voltada a resultados, além de características de gestor estratégico de inovação tecnológica, no caso do diretor industrial, em relação ao desenvolvimento de produtos, e zelo em relação ao processo produtivo da empresa. (Bianchi, Quishida e Foroni, 2017).

Já nas demais áreas (Marketing, Inovação, Agrícola, Recursos Humanos e outras), também expostas na Figura 2, caracterizam-se evidências de discursos com significados demarcados em cada um dos campos de cores, conforme especificado na Tabela 9, que trazem indicações de conexidade entre pessoas e ideias relacionadas entre si, o que sinaliza a comunicação e a interdependência entre as diversas áreas da empresa.

Para Grimsby e Finne Kure (2019), é de salutar relevância para o futuro da indústria de alimentos a compreensão das várias formas de parceria seletiva, colaboração ativa e confiança entre os envolvidos. Nesse contexto, deduz-se que o cenário gerado pela Figura 2 reflete 0 ambiente e a estratégia de inovação no processo de gestão da empresa, bem como a validação do alinhamento e da articulação das mesmas com o modelo de negócio praticado (Vils et al., 2017), em situação que ratifica a confiabilidade das informações, no tocante à interação no ambiente organizacional.

\subsubsection{Resultados da análise por nuvem de palavras da empresa} Alfa

A análise por nuvem de palavras resulta no agrupamento e organização gráfica das palavras em função da frequência das mesmas, conforme exposto na Figura 3.

Denota-se que os vocábulos aleatoriamente posicionados na nuvem de palavras permitem vislumbrar todo um discurso alinhado ao contexto, de forma que as palavras mais frequentes na devolutiva das entrevistas, apareçam destacadas pelo tamanho e cor acentuados, demonstrando, assim, a força de projeção das mesmas.

Pelo resultado da nuvem de palavras torna-se possível observar uma vez mais o nível de correlação entre os vocábulos que obtiveram maior frequência relativa, dentre eles, “empresa”, “alfa”, “inovação”, "produção”, “produto”, "processo", "goiaba", "mercado", "desenvolvimento", "pesquisa", "indústria", "universidade" e "tecnologia", vocábulos estes que ratificam os discursos predominantes nas entrevistas presenciais ou midiáticas.

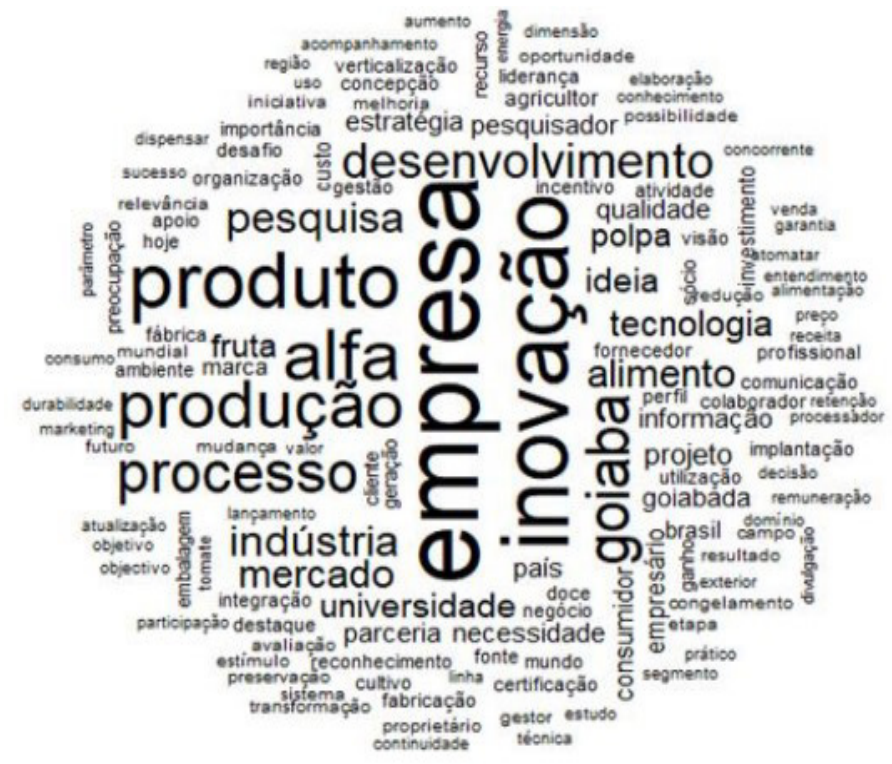

Figura 3. Nuvem de palavras da empresa Alfa Fonte: elaboração própria.

Tabela 9. Identificação dos respondentes, por cor representativa, na Figura 2

\begin{tabular}{|c|c|c|}
\hline Entrevistado & Atuação na empresa & Cor representativa na Figura 2 \\
\hline [E1] & Sócio-diretor (Gestor Principal) & Cor predominante roxa, com trânsito por todas as demais. \\
\hline [E2] & Diretor Industrial & Cor predominante azul, com trânsito por quase todas as demais. \\
\hline [E4] & $\begin{array}{l}\text { Resp. Centro Pesquisa/Inovação em } \\
\text { Alimentos }\end{array}$ & Cor predominante verde-musgo, com trânsito pela cor vermelha. \\
\hline [E6] & Diretor Comercial & Cor predominante amarela, com trânsito pelas cores vermelha, roxa e verde. \\
\hline [E7] & Resp. Finanças & Cor predominante vermelha, com trânsito pelas cores roxa, verde e azul. \\
\hline [E8] & Resp. Recursos Humanos (RH) & Cor predominante rosa, com trânsito pelas cores roxa, verde, azul e amarela. \\
\hline
\end{tabular}

Fonte: elaboração própria. 
Constata-se, dessa forma, que a análise por nuvem de palavras corrobora os resultados explicitados anteriormente na análise de similitude, já que ambas projetam evidências de identificação de discursos muito semelhantes, o que vem a comprovar o rigor metodológico e estatístico do software IRAMUTEQ, principalmente no que se refere à otimização da organização de dados e à avaliação da validade e confiabilidade dos mesmos, bem como no tocante ao resgate do contexto da organização pesquisada, quanto ao zelo em relação ao processo inovativo, associado à identificação organizacional (Camargo e Justo, 2013).

0 cenário exposto permite evidenciar que a análise de similitude e a análise por nuvem de palavras, por meio das conexões apresentadas frente às palavras dos discursos, identificados nas figuras geradas nos respectivos espaços gráficos, a partir dos eixos norteadores expostos, permitem validar os resultados explicitados anteriormente no BMC Canvas em relação ao modelo de negócio e quanto ao ambiente de inovação e alinhamento estratégico no âmbito da empresa, dimensionados através do Octógono da Inovação (Scherer et al., 2009; Vils et al., 2017).

\section{Conclusão}

A motivação deste estudo está associada ao interesse empírico sobre como o modelo de negócio se alinha e articula à estratégia e à capacidade de inovação, no cenário de uma indústria alimentícia brasileira, e como a referida interação é importante no amparo à estrutura organizacional voltada à inovação, no cotidiano da empresa pesquisada.

No tocante aos resultados positivos obtidos no presente estudo, depreende-se do cenário empírico que dois fatores são preponderantes para justificar, a princípio, a divergência em relação a outros estudos: i) o perfil da empresa tomada como estudo de caso, totalmente voltado à inovação, bem como a participação efetiva de um dos sócios-proprietários e principal gestor à frente dos negócios, pelo exercício diário da capacidade pessoal de liderança carismática e ii) pelo feeling para identificar oportunidades e, através delas, ampliar a competitividade da empresa.

Além dos aspectos expostos, alguns outros fatores positivos na organização pesquisada podem ser elencados e denotam a disparidade de resultados em relação aos aspectos críticos - apontados na subseção 2.2 (Estudos Empíricos no Brasil sobre a indústria de alimentos), por outros pesquisadores - aspectos esses elencados a seguir:

i. Baixo nível de investimento e pouca intensidade em $P \& D$ na indústria brasileira de alimentos:

Para dar conta do mercado, a empresa tem apoiado seu crescimento em uma estrutura vertical de produção, que suporta a capacidade de inovação da mesma, tornando-se fator determinante para que o processo inovativo ocorra. Essa dinamização na empresa propicia o surgimento de estratégias tecnológicas de diferenciação, através do aprimoramento de processos e produtos, inclusive com elevada valorização do conhecimento oriundo das universidades, centros de pesquisas e outros órgãos públicos, com forte orquestração entre as funções, como marketing e produção, em ambiente que envolve dependências intraorganizacionais e robusto investimento. 0 processo de inovação na empresa passa por etapas, dentre elas o investimento em $P \& D$, parcerias e equipe exclusiva dedicada à pesquisa em inovação de alimentos.

ii. Caráter incremental das inovações e regime de apropriabilidade frágil:

A empresa pesquisada tem, na estratégia de diversificação e na intensidade do fluxo de lançamentos de novos produtos de alto valor agregado, o seu eixo principal, por reconhecer que o mercado consumidor é muito diverso, com características distintas entre mercados. Dessa forma, a empresa investe tanto em ampliação da capacidade produtiva, quanto no fortalecimento de sua marca. Este é um dos principais fatores de diferenciação e agregação de valor na organização pesquisada.

iii. Dependência excessiva de commodities:

Denota-se que a empresa-alvo apresenta forte desempenho nos manufaturados derivados das commodities, como é o caso dos alimentos processados, inclusive com nichos especiais como as linhas Premium, Light, Livre e Institucional, todas voltadas para atender o life style de consumidores.

iv. Efetividade restrita em inovação organizacional e mercadológica e em relação à competência técnica e operacional de gestão de produtos e processos:

Deduz-se que a dinâmica tecnológica tem efetividade no ambiente de inovação da empresa, a partir da comprovação do alinhamento e articulação com o modelo de negócio dinâmico praticado com a estratégia de inovação e a capacidade de inovação, de forma a contribuir para que os processos de gestão e inovação ocorram em todas as áreas da organização. A utilização eficaz de recursos, aliada a técnicas de planejamento nas ações, resulta em sensível desempenho positivo. Pela observação empírica empreendida é possível inferir que benefícios significativos são obtidos por meio de explícito processo de formulação de estratégias de inovação, coordenadas e direcionadas a um conjunto de metas colocadas como objetivo comum a todos na empresa.

Os aspectos positivos anteriormente expostos demonstram, ainda, não conformidade em relação ao que ocorre, de modo geral, na média das empresas brasileiras de alimentos, no que se refere à inovação, o que justifica, em parte, a alta performance alcançada pela empresa pesquisada.

Nesse cenário, diante das conclusões e dos resultados relevantes obtidos, entende-se que a presente pesquisa possa entregar contribuições empíricas importantes para o universo acadêmico e empresarial, já que o estudo de caso empreendido destaca um processo inovativo, cujas implicações não estão ainda plenamente exploradas em outras pesquisas sobre a indústria alimentícia brasileira. 
0 mapeamento do ambiente de inovação da agroindústria pesquisada, possibilitou o dimensionamento da dinâmica tecnológica na organização, bem como permitiu identificar áreas passíveis de melhorias. Foi possível sugerir aos gestores algumas práticas e estratégias mais assertivas, que melhor contemplem o desenvolvimento da competitividade.

A construção desses resultados apresenta como limitação o escopo da abrangência em relação a outras agroindústrias de alimentos nacionais e multinacionais, não consideradas neste estudo de caso único. Estudos futuros devem incluir um maior número de indústrias globais e locais de alimentos.

Pretende-se que o uso do IRAMUTEQ como ferramenta de apoio à pesquisa para a análise léxica automatizada em Administração de Empresas, seja considerado um diferencial no presente estudo, posto que, na atualidade, referido software é mais usual em pesquisas qualitativas produzidas no âmbito dos programas de pós-graduação nas Áreas de Ciências Humanas, Ciências Sociais e da Saúde lCamargo e Justo, 2013; Pinto, Mazieri e Vils, 2017).

Espera-se que os resultados deste trabalho possam contribuir para ampliar a discussão do processo gerencial que alinha e articula as estratégias e a capacidade de inovação ao modelo de negócio de empresas agroalimentares, com possibilidade de, eventualmente, extrapolar para outras cadeias do agronegócio brasileiro.

\section{Conflito de interesses}

Os autores declaram não haver conflito de interesses.

\section{Referências}

Associação Brasileira da Indústria de Alimentos - Abia. (2019). Indústria de alimentos fecha 2018 com crescimento e geração de empregos. Recuperado em 12 de novembro de 2018, de: https://www.abia.org.br/vsn/tmp_2.aspx?id=3944

Amit, R., \& Zott, C. (2015). Crafting Business Architecture: The Antecedents of Business Model Design. Strategic Entrepreneurship Journal, 9(4), 331 350. https://doi.org/10.1002/sej.1200

Arcese, G., Flammini S., Lucchetti, M.C., \& Martucci, O. (2015). Evidence and Experience of Open Sustainability Innovation Practices in the Food Sector. Sustainability, 7(7), 8067-8090. https://doi.org/10.3390/su7078067

Baden-Fuller, C., \& Morgan, M. S. (2010). Business Models as Models. Long Range Planning, 43(2-3), 156-171. https://doi.org/10.1016/j.Irp.2010.02.005

Bencke, F. F., Gilioli, R. M., \& Royer, A. (2018). Inovação disruptiva: uma análise das pesquisas empíricas publicadas no Brasil. Revista Brasileira de Gestão e Inovação, 5(2), 159-180. http://doi.org/10.18226/23190639.v5n2.07

Bianchi, E. M. P. G., Quishida, A., \& Foroni, P. G. (2017). Atuação do Líder na Gestão Estratégica de Pessoas: Reflexões, Lacunas e Oportunidades. Revista de Administração Contemporânea, 21(1), 41-61. https://doi.org/10.1590/19827849rac2017150280

Bonazzi, F. L. Z., \& Zilber, M. A. (2014). Inovação e Modelo de Negócio: um estudo de caso sobre a integração do Funil de Inovação e o Modelo Canvas. Revista Brasileira de Gestão de Negócios, 16(53), 616-637. https://doi.org/10.7819/rbgn.v16i52.1812

Brem, A., \& Viardot, E. (2017). Revolution of Innovation Management: Internationalization and Business Models. In: A. Brem, \& E. Viardot (Eds.) Revolution of Innovation Management: Internationalization and Business Models (pp. 1-13). London: Palgrave Macmillan. https://doi.org/10.1057/978-1-349-95123-9_1
Bresciani, S. (2017). Open, networked and dynamic innovation in the food and beverage industry. British Food Journal, 119(1), 2290-2293. https://doi.org/10.1108/BFJ-08-2017-0458

Cabral, J. E.O. (2007). Determinantes da propensão para inovar e da intensidade inovativa em empresas da indústria de alimentos do Brasil. Revista de Administração Contemporânea, 11(4), 87-108. https://doi.org/10.1590/S1415-65552007000400005

Camargo, B. V., \& Justo, A. M. (2013). IRAMUTEQ: um software gratuito para análisede dados textuais. Temas em Psicologia, 21(2), 513-518. https://doi.org/10.9788/TP2013.2-16

Casadesus-Masanell, R., \& Ricart, J. E. (2010). From strategy to business models and onto tactics. Long Range Planning, 43(2-3), 195-215. https://doi.org/10.1016/j.lrp.2010.01.004

Ceretta, G. F., Reis, D. R., \& Rocha, A. C. (2016). Inovação e modelos de negócio: um estudo bibliométrico da produção científica na base Web of Science. Gestão \& Produção, 23(2), 433-444. https://doi.org/10.1590/0104-530x1461-14

César, A. S., Mori, C., \& Batalha, M. 0 (2010). Inovações tecnológicas de embalagens nas indústrias de alimentos: estudo de caso da adoção de embalagem ativa em empresas de torrefação de café. Revista Brasileira de Inovação, 9(2), 355-378. https://doi.org/10.20396/rbi.v9i2.8649005

Cheng, C. F., Chang, M. L., \& Li, C. S. (2013). Configural paths to successful product innovation. Journal of Business Research, 66(12), 2561-2573. https://doi.org/10.1016/j.jbusres.2012.10.006

Chesbrough, H. (2010). Business model innovation: opportunities and barriers. Long Range Planning, 43(2-3), 354-363. https://doi.org/10.1016/j.lrp.2009.07.010

Christensen, C. M. (1997). The innovator's dilemma: when new technologies cause great firms to fail. Boston: Harvard Business Review Press.

Conceição, J.C.P.R., \& Almeida, M. (2005). Inovação na Indústria de Alimentos no Brasil: identificação dos principais fatores determinantes. In: Negri, J. A.; Salerno, M. S. (Org.). Inovações, Padrões Tecnológicos e Desempenho das Firmas Industriais Brasileiras (pp. 599-651). Brasília: Ipea.

Da Silva, C. M., \& Trkman, P. (2014). Business model: what it is and what it is not. Long Range Planning, 47(6), 379-389. https://doi.org/10.1016/j.trp.2013.08.004

Del Carpio Gallegos, J. F., \& Miralles, F. (2018). Impacto de las fuentes externas de conocimiento en la innovación de productos de empresas de baja y media baja intensidad tecnológica. Estudios Gerenciales, 34(149), 435-444. https://doi.org/10.18046/j.estger.2018.149.2874

Demil, B., Lecocq, X., Ricart, J.E., \& Zott, C. (2015). Introduction to the SEJ special issue on business models: business models within the domain of strategic entrepreneurship. Strategic Entrepreneurship Journal, 9(1) 1-11. https://doi.org/10.1002/sej.1194

Dosi, G. (1988). The nature of the innovative process. In: Dosi, G. et al. (eds) Technical change and economic theory (pp.221-238). London: Pinter Publishers.

Empresa Brasileira de Pesquisa Agropecuária (Embrapa) \& Centro de Gestão e Estudos Estratégicos (CGEE). (2014). Sustentabilidade e sustentação da produção de alimentos no Brasil: 0 papel do País no cenário global. Brasília: Embrapa.

Franceschelli, M. V., Santoro, G., \& Candelo, E. (2018). Business model innovation for sustainability: a food start-up case study. British Food Journal, 120(10), 2483-2494. https://doi.org/10.1108/BFJ-01-2018-0049

Frank, A. G., Cortimiglia, M. N., Ribeiro, J. L. D., \& Oliveira, L. S. (2016). The effect of innovation activities on innovation outputs in the brazilian industry: market-orientation vs. Technology-acquisition strategies. Research Policy, 45(3), 577-592. https://doi.org/10.1016/j.respol.2015.11.01

Freeman, C. (1975). La teoría económica de la innovación industrial. Madrid: Alianza.

Gianezini, M., Alves, A. B., Techemayer, C. A., \& Révillion, J. P. P. (2012). Diferenciação de produto e inovação na indústria agroalimentar: a inserção de alimentos funcionais no Brasil. Revista de Administração, Contabilidade e Economia, 11(1), 9-26.

Ginting, G. (2015). Open Innovation Model: Empowering Entrepreneurial Orientation and Utilizing Network Resources as Determinant for Internationalization Performance of Small Medium Agroindustry. Agriculture and Agricultural Science Procedia, 3, 56-61. https://doi.org/10.1016/j.aaspro.2015.01.013

Gouveia, F. (2006). Indústria de alimentos: no caminho da inovação e de novos produtos. Inovação Uniemp, (2)5, 32-37. 
Grimsby, S., \& Finne Kure, C. (2019). How open is food innovation? The crisp bread case. British Food Journal, 121(4), 950-963. https://doi.org/10.1108/BFJ-07-2018-046

Instituto Brasileiro de Geografia e Estatística -IBGE. (2017). Pesquisa Industrial de Inovação Tecnológica (Pintec)2014/2017. Rio de Janeiro: IBGE.

Lopes, A. P., Kissimoto, K., Salerno, M., Carvalho, M., \& Laurindo, F. (2016). Innovation management: a systematic literature analysis of the innovation management evolution. Brazilian Journal of Operations \& Production Management, 13(1), 16-30. https://doi.org/10.14488/BJOPM.2016.v13.n1.a2

MCguirk, H., Lenihan, H., \& Hart, M. (2015). Measuring the impact of innovative human capital on small firms' propensity to innovate. Research Policy, 44, 965-976. https://doi.org/10.1016/j.respol.2014.11.008

Nagano, M. S., Stefanovitz, J. P., \& Vick, T. E. (2014). Innovation management processes, their internal organizational elements and contextual factors: an investigation in Brazil. Journal of Engineering and Technology Management, 33,63-92. https://doi.org/10.1016/j.jengtecman. 2014.02.004

Osterwalder, A. (2004). The business model ontology: a proposition in a design science approach [Doctoral dissertation, University of Lausanne]. HEC repository.

Osterwalder A., \& Pigneur, Y. (2010). Business Model Generation: a Handbook for Visionaries, Game changers, and Challengers. London: John Wiley \& Sons.

Pinto, J.C., Mazieri, M.R., \& Vils, L. (2017). Análise Léxica Automatizada em Administração de Empresas. Anais do VISINGEP - São Paulo - SP - Brasil. Recuperado em 12 de novembro de 2018, de: http://singep.submissao. com.br/6singep/resultado/an_resumo.asp?cod_trabalho $=578$

Quandt, C. (2012). Redes de cooperação e inovação localizada: estudo de caso de um arranjo produtivo local. INMR - Innovation \& Management Review, 9(1), 141-166.

Raimundo, L. M. B., Batalha, M. 0, \& Torkomian, A. L. V. (2017). Dinâmica tecnológica da Indústria Brasileira de Alimentos e Bebidas (2000-2011). Gestão \& Produção, 24(2), 423-436 https://doi.org/10.1590/0104-530x2750-15

Ramos, A., \& Zilber, S. (2015). 0 impacto do investimento na capacidade inovadora da empresa. INMR - Innovation \& Management Review, 12(1), 303-325.

Ratinaud, P., \& Marchand, P. (2012). Recherche improbable d'une homogène diversité: le débat sur l'identité nationale. Langages, (3), 93-107.

Révillion, J. P. P. (2011). Inovação e diferenciação de produtos agroindustriais. In: Révillion, J. P. P., \& Badejo, M. S. Gestão e Planejamento de Organizações Agroindustriais (pp. 9-44). Porto Alegre: UFRGS.

Santos, V. \& Magrini, A. (2018). Biorefining and industrial symbiosis: A proposal for regional development in Brazil. Journal of Cleaner Production, 177, 19-33. https://doi.org/10.1016/j.jclepro.2017.12.107

Scaciotta, V., Guerrazzi, L., \& Fernandes, K. (2019). Em Busca de Convergência: Um Estudo Bibliométrico sobre Modelo de Negócios. Revista Iberoamericana de Estratégia, 18(1), 4-18. https://doi.org/10.5585/ijsm.v18i1.2708

Scherer, F. O., Bignetti, L. P., \& Carlomagno, M. S. (2009). Os tipos de inovação. Innoscience consultoria em gestão da inovação. Recuperado em 10 de dezembro de 2017, de: http://www.innoscience.com.br

Scherer, F. O. \& Carlomagno, M. S. (2009). Gestão da inovação na prática: como ampliar conceitos e ferramentas para alavancar a inovação. São Paulo: Atlas.

Sidonio, L., Capanema, L., Guimarães, D. D., \& Carneiro, J. V.A. (2013). Inovação na indústria de alimentos : importância e dinâmica no complexo agroindustrial brasileiro. Agroindústria BNDES Setorial, 37, 333-370.

Stefanovitz, J. P., \& Nagano, M. S. (2014). Gestão da inovação de produto: proposição de um modelo integrado. Production, 24(2), 462-476. http://dx.doi.org/10.1590/S0103-65132013005000062

Tarapuez, E., Guzmán, B. E., \& Parra-Hernández, R. (2016). Estrategia e innovación en las Mipymes colombianas ganadoras del premio Innova 2010-2013. Estudios Gerenciales, 32(139), 170-180. https://doi.org/10.1016/j.estger.2016.01.002

Teece, D.J. (2010). Business models, business strategy and innovation. Long Range Planning, 43(2-3), 172-194. https://doi.org/10.1016/j.lrp.2009.07.003

Vils, L., Mazzieri, M. R., Rodrigues, G. V., Da Silva, A. R., \& de Queiroz, M.J. (2017). Business Model Innovation: A Bibliometric Review. International Journal of Innovation, 5(3), 311-310. https://doi.org/10.5585/iji.v5i3.243
Wu, J. (2011). The asymmetric roles of business ties and political ties in product innovation. Journal of Business Research, 64(11), 1151-1156. https://doi.org/10.1016/j.jbusres.2011.06.014

Zhao, X., Pan, W., \& Chen, L. (2018). Disentangling the relationships between business model innovation for low or zero carbon buildings and its influencing factors using structural equation modelling, Journal of Cleaner Production, 178, 154-165. https://doi.org/10.1016/j.jclepro.2018.01.010 